\title{
66. PHYSICAL PROPERTIES OF BASALTS FROM HOLES 417D AND 418A
}

\author{
Yozo Hamano, Geophysical Institute, Faculty of Sciences, University of Tokyo, Tokyo, Japan
}

\section{INTRODUCTION}

Legs 51-53 of the Deep Sea Drilling Project drilled three deep holes (Holes 417A, 417D, and 418A) at the southwest end of the Bermuda Rise. These sites are located on magnetic anomaly $M O$ and the basement is estimated to be about $100 \mathrm{~m} . \mathrm{y}$. old. These holes penetrated into the basement layer by 209 (417A), 365.5 (417D), and 544 meters (418A), respectively. The good recovery in these holes assures that the recovered basement rocks are representative of the upper part of Layer 2 at the sites.

In the present paper the results of the physical property measurements on the basement rock samples from Holes 417D and 418A are presented and their implications are discussed. The physical properties examined are bulk density, porosity, compressional wave velocity, shear wave velocity, electrical resistivity, thermal conductivity, and air permeability. Grain density, water content, Poisson's ratio, and other elastic constants are derived from the above observations. All the physical properties except porosity and air permeability were measured on sea-water-saturated samples, since, for geophysical purposes, it is important to know the physical properties of the basement rocks under in situ conditions.

From seismic experiments, Layer 2 is subdivided into three Layers (2A, 2B, and 2C). Previous DSDP sites in which deep penetration into basement was attained are located in relatively young ocean crust and the recovered rocks are mostly from Layer $2 \mathrm{~A}$, whereas the top of the basement of the present sites is considered to be part of Layer 2B. Comparison of the presently observed physical properties to earlier results, therefore, provides useful information on the structure of the oceanic crust. Alternatively, the relation of seismic velocity to other physical properties can be used to estimate the in situ physical properties of Layer 2, since the oceanic crust has been mainly investigated by seismic refraction experiments and other physical properties are only indirectly known. In the present study many physical properties were measured on each specimen in order to provide a quantitative basis for such a discussion.

\section{EXPERIMENTS}

Measurements of physical properties were made both on board Glomar Challenger and in our laboratory. Each specimen was cut to the shape of a right cylinder with a $2.53-\mathrm{cm}$ diameter and a height of about $2.5 \mathrm{~cm}$. In order to preserve their in situ properties, each specimen was kept in sea water between measurements and during transportation to our laboratory. Although the minicores had to be taken out of sea water during each measurement, the disturbance can be neglected because of their slow drying rate.

The physical properties measured on board were bulk density, porosity, and compressional wave velocity. Two methods were employed to measure the bulk density on each minicore. These were the GRAPE (Gamma Ray Attenuation Porosity Evaluator) 2-minute counting procedure (Boyce, 1976) and a standard gravimetric immersion technique (Hyndman and Drury, 1977). In the present study the estimated accuracies are \pm 2 per cent (GRAPE) and \pm 1 per cent (immersion technique), respectively. Comparison of the results of the two measurements indicates that the two methods give consistent values within the accuracy cited above (Site 417 and 418 Reports, this volume).

The porosity measurements were carried out by weighing sea-water-saturated minicores before and after drying for 24 hours at $110^{\circ} \mathrm{C}$. As discussed by Hyndman and Drury (1977), the observed porosity may give a minimum estimate. A comparison of the porosity values obtained by slightly different techniques on Legs 51,52 , and 53 suggests that the values reported here are accurate to \pm 5 per cent.

Compressional wave velocities were measured with the Hamilton Frame velocimeter onboard ship. The experimental procedure as well as the precision of the technique are given by Boyce (1976). In the present study the compressional wave velocity was measured in three different directions on each minicore sample. The velocities in the vertical and horizontal directions show no systematic discrepancy. The isotropic property of Layer 2 basalts has been observed previously (Christensen and Salisbury, 1975). The results of the above measurements are reproducible to \pm 1.5 per cent.

After completion of the shipboard studies, the minicores from Holes 417D and 418A were brought to our laboratory for studies of compressional- and shear-wave velocity, bulk density, thermal conductivity, electrical resistivity, and air permeability. The bulk densities were measured by an immersion technique similar to that used on shipboard. The accuracy of the measurement, \pm 0.5 per cent, is better than that of the shipboard measurement due to the lack of ship movement and the use of a precise balance.

A standard pulse transmission method was employed to measure compressional and shear wave velocities. The high frequencies used ( 2 and $1 \mathrm{mHz}$ for $\mathrm{V}_{\mathrm{p}}$ and $\mathrm{V}_{\mathrm{s}}$, respectively), compared to that used in the Hamilton Frame $(400 \mathrm{kHz})$, allowed measurements to be made to an accuracy of \pm 1 per cent. In addition, the compressional wave velocity of some basalt samples was measured as a function of hydrostatic confining pressure to $1 \mathrm{kbar}$. The mercury delay line employed for this measurement permitted velocity measure- 
ments to be made with an accuracy of about \pm 0.05 per cent. The bulk density and compressional wave velocity of five samples were measured both onboard ship and in our laboratory. The observed values agree with each other to within the experimental error and show no systematic discrepancies. Although there are not enough data to prove the consistency of the measurements in a statistical sense, we combine both data sets in later discussions. Similar trends observed in the velocity/density relations of the two data sets also tend to confirm the accuracy of the observations.

The electrical resistivity measurements were carried out at room temperature using a commercial $\mathrm{AC}$ bridge with a frequency of $1 \mathrm{kHz}$. The frequency dependence of the resistivity was examined on some samples for a frequency range of $100 \mathrm{~Hz}$ to $1 \mathrm{MHz}$. As has been observed previously (Katsube et al., 1977), the frequency dependence of seawater-saturated samples in this frequency range is small. The data shown in Table 1 are therefore $1 \mathrm{kHz}$ values. The accuracy of the measurement was about \pm 5 per cent.

The thermal conductivity was measured by a QTM-1 thermal conductivity meter made by Showa Denko, which uses a modified needle-probe technique. Because the apparatus is designed to measure samples with a large flat surface $(5 \mathrm{~cm} \times 10 \mathrm{~cm})$, it had to be recalibrated for the present study. Due to the small thermal conductivity of the basalt samples, the correction factor was only about \pm 5 per cent. The nominal precision of the apparatus is \pm 5 per cent, but the reproducibility of the measurement, when the sensor was carefully set, was better than \pm 2 per cent.

Permeability measurements were carried out with a commercial gas-oil test machine which used compressed air for the fluid medium. A pressure difference of about 7 bars was employed, together with a circumferential pressure of 20 bars to avoid surface flow. The volume of air which passed through each sample was measured precisely by a small pipette to obtain the permeability. The flow rate was between $0.001 \mathrm{~cm}^{3} / \mathrm{min}$ and $1 \mathrm{~cm}^{3} / \mathrm{min}$. It took about 30 minutes to measure the most impermeable sample. The short measuring time, realized by using air instead of water, minimized environmental change during the measurement.

With the exception of the permeability data, the results of the physical property measurements made in our laboratory are listed in Table 1, whereas those of the shipboard measurements are shown in the Site 417 and Site 418 Reports (this volume). The average properties of the basalt samples from both sets of measurements are given in Table 2. The observed permeabilities are presented separately in Table 3 . Figure 1 presents histograms of the observed properties. The wide variation of the physical properties of DSDP samples has been observed previously and the ranges of the observed values are not significantly different from the earlier results.

\section{POROSITY DEPENDENCE OF THE BULK DENSITY AND THE COMPRESSIONAL WAVE VELOCITY}

In Figures 2 and 3, the observed bulk density and the compressional wave velocity were plotted against the porosity observed on the same core sample. Strong correlation of both properties with the porosity is evident. This indicates that the variations of the bulk density and the compressional wave velocity are largely controlled by the volume fraction of pores, i.e., the water content in the samples, and that variations of the intrinsic (pore-free) properties are comparatively small. The homogeneity of the chemical and mineral compositions observed in the present basalt samples (Site Reports, this volume) supports the above conclusion. Linear extrapolation of the above trends to zero porosity therefore approximates the intrinsic physical properties of the oceanic basalts. The estimated intrinsic properties are $2.96 \pm 0.02$ $\mathrm{g} / \mathrm{cm}^{3}$ (density) and $6.26 \pm 0.10 \mathrm{~km} / \mathrm{s}$ (velocity), respectively. This density is close to the theoretical density of basalts from Hole 417D, about $3.00 \mathrm{~g} / \mathrm{cm}^{3}$, calculated from the composition of basaltic glasses (Bryan, personal communication). The compressional wave velocity is close to the highest laboratory velocity observed in oceanic basalts (Christensen and Salisbury, 1975). More realistic non-linear extrapolations using the Reuss model (Birch, 1966) may give a higher intrinsic velocity of about $6.4 \mathrm{~km} / \mathrm{s}$.

In Figure 2, a line fitted by the least-squares method (solid line) and a theoretical line (dotted line) are shown. The theoretical line was calculated assuming replacement of the solid phase (intrinsic density $2.96 \mathrm{~g} / \mathrm{cm}^{3}$ ) by sea water with a density of $1.03 \mathrm{~g} / \mathrm{cm}^{3}$ as the porosity increases. The lower slope of the least-squares line suggests either that the porosity value is underestimated or that some low density secondary material such as clay increases with increasing porosity. In either case, the extrapolated pore-free density might be a better estimate of the intrinsic rock density than the grain density calculated for individual samples.

\section{DENSITY DEPENDENCE OF COMPRESSIONAL WAVE VELOCITY, SHEAR WAVE VELOCITY, ELECTRICAL RESISTIVITY, AND THERMAL CONDUCTIVITY}

The relations of the observed shear wave velocity, electrical resistivity, and thermal conductivity to the bulk density are shown in Figures $4 \mathrm{a}, 4 \mathrm{~b}$, and $4 \mathrm{c}$ respectively, and the compressional wave velocity/density relation is shown in Figure 5. Significant correlations are observed in these figures. The velocity/density relations are attributed to the variation of the velocity and density with the porosity discussed above. The meaning of the relation is therefore different from the velocity/density relations compiled by Birch (1961) and by Nafe and Drake (1968), in which the variation of the intrinsic velocity with density was considered.

The electrical resistivity/density relation (Figure $4 \mathrm{~b}$ ) indicates that the electrical resistivity varies about two orders of magnitude (20-2000 ohm-m) as the density changes from $2.7 \mathrm{~g} / \mathrm{cm}^{3}$ to $2.95 \mathrm{~g} / \mathrm{cm}^{3}$. As is widely known (e.g., Parkhomenko, 1967), the low resistivity of many rocks is due to water contained in pores and the intrinsic resistivity of the rocks is much greater than values noted above. Thus the variation of the electrical resistivity must also be affected by the water content. Because of the nonlinear change of resistivity in wet rocks (Parkhomenko, 1967), it is not possible to obtain the intrinsic resistivity from the present observations.

As can be seen in Figure 4c, the observed thermal conductivity also correlates with the density, although the range of variation (about 4.0 to $4.6 \mathrm{mcal} / \mathrm{cm}^{2} \mathrm{~s}^{\circ} \mathrm{C}$ ) is relatively small. Robertson and Peck (1974) measured the thermal 
TABLE 1

Physical Properties of Basement Rocks From Holes 417D and 418A

\begin{tabular}{|c|c|c|c|c|c|}
\hline $\begin{array}{c}\text { Sample } \\
\text { (Interval in } \mathrm{cm} \text { ) }\end{array}$ & $\begin{array}{l}\text { Density } \\
\left(\mathrm{g} / \mathrm{cm}^{3}\right)\end{array}$ & $\begin{array}{l}\text { Compressional } \\
\text { Wave Velocity } \\
(\mathrm{km} / \mathrm{s})\end{array}$ & $\begin{array}{l}\text { Shear Wave } \\
\text { Velocity } \\
(\mathrm{km} / \mathrm{s})\end{array}$ & $\begin{array}{c}\text { Thermal } \\
\text { Conductivity } \\
\text { (mcal/cm s } \mathrm{s}^{\circ} \mathrm{C} \text { ) }\end{array}$ & $\begin{array}{l}\text { Electrical } \\
\text { Resistivity } \\
\text { (ohm-m) }\end{array}$ \\
\hline \multicolumn{6}{|l|}{ Hole 417D } \\
\hline $22-1,141-143$ & 2.78 & 5.23 & 2.93 & 4.22 & 58 \\
\hline $26-1,90-92$ & 2.77 & 5.07 & 2.79 & 4.06 & 61 \\
\hline $27-1,119-121$ & 2.82 & 5.60 & 3.10 & 4.24 & 103 \\
\hline $28-2,54-56$ & 2.70 & 5.08 & 2.85 & 4.08 & 36 \\
\hline $29-1,88-90$ & 2.74 & 5.17 & 2.76 & 4.11 & 41 \\
\hline $30-5,123-126$ & 2.75 & 5.24 & 2.84 & 4.07 & 78 \\
\hline $31-3,74-76$ & 2.82 & 5.50 & 3.06 & 4.29 & - \\
\hline $32-5,133-135$ & 2.87 & 5.83 & 3.28 & 4.50 & 151 \\
\hline $33-5,9-11$ & 2.87 & 5.94 & 3.24 & 4.40 & 121 \\
\hline $34-2,60-63$ & 2.88 & 5.94 & 3.31 & 4.43 & 223 \\
\hline $35-5,147-149$ & 2.83 & 5.84 & 3.25 & 4.29 & 210 \\
\hline $36-1,124-126$ & 2.86 & 5.64 & 3.00 & 4.09 & 53 \\
\hline $37-5,23-25$ & 2.76 & 5.67 & 3.13 & 4.05 & 87 \\
\hline $38-4,83-86$ & 2.89 & - & - & 4.39 & - \\
\hline $39-4,94-96$ & 2.82 & 5.61 & 3.10 & 4.28 & 145 \\
\hline $40-1,90-92$ & 2.78 & 5.50 & 3.08 & 4.22 & 101 \\
\hline $41-5,96-98$ & 2.87 & 5.85 & 3.28 & 4.52 & 598 \\
\hline $42-5,135-137$ & 2.87 & 5.60 & 3.09 & 4.33 & 69 \\
\hline $43-4,144-146$ & 2.84 & 5.57 & 3.02 & 4.45 & 75 \\
\hline $44-3,83-85$ & 2.84 & 5.73 & 3.11 & 4.36 & 79 \\
\hline $45-2,32-34$ & 2.74 & 4.98 & 2.59 & 4.21 & 33 \\
\hline $48-6,58-60$ & 2.78 & - & - & 4.30 & 32 \\
\hline $49-2,38-40$ & 2.70 & - & - & 4.12 & 20 \\
\hline $52-2,113-115$ & 2.92 & - & - & 4.51 & 141 \\
\hline $52-4,125-127$ & 2.83 & - & - & 4.28 & 89 \\
\hline $54-4,98-100$ & 2.88 & - & - & 4.32 & 203 \\
\hline $55-1,131-133$ & 2.88 & 5.74 & 3.13 & 4.33 & 75 \\
\hline $59-3,7-9$ & 2.81 & 5.47 & 3.07 & 4.22 & 76 \\
\hline $60-2,44-46$ & 2.76 & 5.36 & 2.98 & 4.08 & 51 \\
\hline $62-3,21-23$ & 2.74 & 5.18 & 2.77 & 4.03 & 51 \\
\hline $65-6,30-32$ & 2.77 & 5.50 & 3.06 & 4.30 & 53 \\
\hline $66-4,144-147$ & 2.75 & 5.35 & 2.97 & 4.13 & 70 \\
\hline $67-2,80-83$ & 2.89 & 5.86 & 3.27 & 4.44 & 325 \\
\hline \multicolumn{6}{|l|}{ Hole 418A } \\
\hline $42-1,88-90$ & 2.48 & 4.90 & 2.70 & 4.21 & 39 \\
\hline $43-1,11-13$ & 2.81 & 5.68 & 3.17 & 4.17 & 239 \\
\hline $45-1,86-89$ & 280 & 5.77 & 3.24 & 4.13 & 283 \\
\hline $46-3,8-10$ & 2.86 & 5.79 & 3.29 & 4.21 & 1714 \\
\hline $48-3,106-109$ & 2.84 & 5.83 & 3.23 & 4.30 & - \\
\hline $49-1,21-23$ & 2.81 & 5.69 & 3.10 & 4.23 & - \\
\hline $50-3,130-132$ & 2.87 & 5.73 & 3.18 & 4.42 & 264 \\
\hline $52-7,8-10$ & 2.85 & 5.79 & 3.23 & 4.34 & - \\
\hline $53-3,21-23$ & 2.86 & 5.64 & 3.14 & - & 197 \\
\hline $56-6,127-129$ & 2.86 & 5.86 & 3.25 & 4.53 & - \\
\hline $57-6,4-6$ & 2.90 & 5.62 & 3.06 & 4.50 & 140 \\
\hline $59-6,53-55$ & 2.77 & 5.28 & 2.85 & 4.29 & - \\
\hline $60-4,43-45$ & 2.73 & 5.15 & 2.82 & - & 43 \\
\hline $61-1,7-9$ & 2.90 & 5.90 & 3.28 & 4.51 & - \\
\hline $62-1,80-82$ & 2.83 & 5.53 & 3.06 & 4.15 & - \\
\hline $63-2,11-13$ & 2.81 & 5.23 & 2.79 & 4.30 & 90 \\
\hline $644,131-133$ & 2.76 & 5.36 & 2.91 & 4.17 & - \\
\hline $65-4,103-105$ & 2.69 & 4.94 & 2.70 & 4.14 & - \\
\hline $66-6,132-134$ & 2.89 & 5.81 & 3.19 & 4.25 & 96 \\
\hline $68-2,98-100$ & 2.91 & 6.09 & 3.40 & 4.41 & - \\
\hline $69-4,80-82$ & 2.92 & 6.00 & 3.28 & 4.41 & - \\
\hline $73-6,33-35$ & 2.87 & 5.82 & 3.18 & 4.62 & 149 \\
\hline $74-4,134-136$ & 2.94 & 6.14 & 3.37 & 4.52 & - \\
\hline $76-1,119-121$ & 2.88 & 5.87 & 3.22 & 4.37 & - \\
\hline $77-2,22-24$ & 2.91 & 5.88 & 3.23 & 4.62 & 318 \\
\hline $77-3,73-75$ & 2.91 & 6.14 & 3.40 & 4.57 & - \\
\hline $79-7,46-48$ & 2.90 & 5.99 & 3.28 & - & 581 \\
\hline $80-2,90-92$ & 2.93 & 6.23 & 3.45 & 4.38 & - \\
\hline $80-3,67-69$ & 2.92 & 6.14 & 3.32 & 4.43 & 1187 \\
\hline $83-4,82-84$ & 2.89 & 5.85 & 3.14 & 4.64 & - \\
\hline $84-3,137-139$ & 2.95 & 6.11 & 3.38 & - & 338 \\
\hline $85-5,23-25$ & 2.93 & 6.18 & 3.35 & 4.63 & - \\
\hline $86-4,108-110$ & 2.81 & 5.64 & 3.03 & 4.22 & 245 \\
\hline
\end{tabular}


TABLE 2

Average Physical Properties of Basement Rocks

\begin{tabular}{|c|c|c|c|c|c|c|}
\hline \multirow[b]{2}{*}{$\begin{array}{c}\text { Physical } \\
\text { Properties }\end{array}$} & \multicolumn{3}{|c|}{ Present Results } & \multicolumn{3}{|c|}{ Leg 37 Basalts $^{a}$} \\
\hline & $\begin{array}{c}\text { Number } \\
\text { of } \\
\text { Samples }\end{array}$ & Mean & $\begin{array}{l}\text { Standard } \\
\text { Deviation }\end{array}$ & $\begin{array}{c}\begin{array}{c}\text { Number } \\
\text { of } \\
\text { Samples }\end{array} \\
\text { Sam }\end{array}$ & Mean & $\begin{array}{l}\text { Standard } \\
\text { Deviation }\end{array}$ \\
\hline Compressional wave velocity $(\mathrm{km} / \mathrm{s})$ & 189 & 5.48 & 0.48 & 79 & $5.94^{\mathrm{b}}$ & 0.34 \\
\hline Shear wave velocity $(\mathrm{km} / \mathrm{s})$ & 65 & 3.10 & 0.21 & 37 & $3.27^{\mathrm{b}}$ & 0.15 \\
\hline Poisson's ratio & 65 & 0.282 & 0.011 & 37 & $0.295^{\mathrm{b}}$ & 0.011 \\
\hline Bulk density $\left(\mathrm{g} / \mathrm{cm}^{3}\right)$ & 185 & 2.785 & 0.128 & 101 & 2.795 & 0.082 \\
\hline Porosity (\% volume) & 104 & 8.4 & 5.5 & 85 & 7.8 & 4.1 \\
\hline Grain density $\left(\mathrm{g} / \mathrm{cm}^{3}\right)$ & 104 & 2.914 & 0.042 & 85 & 2.949 & 0.045 \\
\hline Thermal conductivity $\left(\mathrm{mcal} / \mathrm{cm} \mathrm{s}^{\circ} \mathrm{C}\right)$ & 64 & 4.31 & 0.17 & 19 & 3.97 & 0.17 \\
\hline Electrical resistivity (ohm-m) & 48 & $120^{\mathrm{c}}$ & - & 87 & 220 & - \\
\hline Air permeability $\left(\mathrm{cm}^{2}\right)$ & 16 & $1.1 \times 10^{-16^{\mathrm{c}}}$ & - & - & - & - \\
\hline
\end{tabular}

${ }^{\mathrm{a}}$ Hyndman and Drury (1976).

$\mathrm{b}_{0.5}$ kbar.

${ }^{\mathrm{c}}$ Geometric mean.

TABLE 3

Air Permeability and Electrical Resistivity

\begin{tabular}{lcr}
\hline $\begin{array}{c}\text { Sample } \\
\text { (Interval in cm) }\end{array}$ & $\begin{array}{c}\text { Air } \\
\text { Permeability } \\
\left(\mathrm{cm}^{2}\right)\end{array}$ & $\begin{array}{c}\text { Electrical } \\
\text { Resistivity } \\
\text { (ohm-m) }\end{array}$ \\
\hline Hole 417D & & \\
$26-1,90-92$ & $1.6 \times 10^{-15}$ & 61 \\
$30-5,123-126$ & $2.7 \times 10^{-15}$ & 78 \\
$35-5,147-149$ & $5.5 \times 10^{-15}$ & 210 \\
$39-4,94-96$ & $2.3 \times 10^{-16}$ & 145 \\
$41-5,96-98$ & $2.8 \times 10^{-14}$ & 598 \\
$43-4,144-146$ & $4.6 \times 10^{-15}$ & 75 \\
$45-2,32-34$ & $1.9 \times 10^{-15}$ & 33 \\
$49-2,38-40$ & $1.7 \times 10^{-15}$ & 20 \\
$59-3,7-9$ & $4.0 \times 10^{-15}$ & 76 \\
& & \\
Hole 418A & & \\
$46-3,8-10$ & $1.0 \times 10^{-15}$ & 1714 \\
$53-3,21-23$ & $3.2 \times 10^{-15}$ & 197 \\
$77-2,22-24$ & $2.9 \times 10^{-17}$ & 318 \\
$79-7,46-48$ & $5.4 \times 10^{-17}$ & 581 \\
$80-3,67-69$ & $2.7 \times 10^{-17}$ & 1187 \\
$84-3,21-23$ & $5.5 \times 10^{-15}$ & 338 \\
$86-4,108-110$ & $4.9 \times 10^{-16}$ & 245 \\
\hline
\end{tabular}

conductivity of vesicular basalts from Hawaii over a wide range of porosity ( 2.0 to $98 \%$ ). The presently observed values and the variation are similar to their results for water-saturated samples with low porosity (up to $10 \%$ ). The correlation between thermal conductivity and density is therefore attributed to differences in the porosity or water content of the present samples, whereas the scatter of the data is probably due to differences in mineral composition.

\section{AIR PERMEABILITY AND ELECTRICAL RESISTIVITY}

The results of the permeability measurements are summarized in Table 3; electrical resistivity values obtained for the same samples are also listed for comparison. Unlike the relations between physical properties discussed above, the observed air permeability does not show an obvious correlation with other physical properties. The sensitivity of permeability to structure may contribute to the scatter of the data. On the basis of a simple capillary model (Scheidegger, 1960), the permeability, $\mathrm{k}$, is expressed as

$$
\mathrm{k}=\frac{\mathrm{h}^{2}}{4 \pi \mathrm{s}} \phi \mathrm{T}^{-2}
$$

where $\phi$ is the porosity, T is the tortuosity, h is the mean thickness of the pores, and $\mathrm{s}$ is a shape factor close to unity. As shown in Equation 1, the permeability varies with the thickness of the pores even if the porosity is kept constant. From the same capillary model the electrical resistivity, $r$, and the porosity are related by the function,

$$
r=r_{f} \phi^{-1} T^{2},
$$

where $\mathrm{r}_{\mathrm{f}}$ is the electrical resistivity of the fluid saturating the pore space. Combining Equations 1 and 2 gives

$$
k\left(\frac{r}{r_{f}}\right)=\frac{h^{2}}{4 \pi s}
$$

Thus, the product of the permeability and the electrical resistivity ratio gives the mean thickness of the pores in the rocks. The resistivity-permeability relation for the present samples is shown in Figure 6 for sea-water-saturated samples at room temperature $\left(r_{f}=0.25 \mathrm{ohm}-\mathrm{m}\right)$. The wide scatter of the data is probably due to the sensitivity of permeability to pore width. Brace et al. (1968) observed a clear relationship between permeability and electrical resistivity in granite as a function of hydrostatic confining pressure, and Brace (1977) indicated that

$$
\mathrm{k} \propto\left(\frac{\mathrm{r}}{\mathrm{r}_{\mathrm{f}}}\right)^{-1.5}
$$

This relationship was not observed in the present study.

The observed range of permeability is much smaller than the value estimated or expected from hydrothermal circulation at oceanic spreading centers (Lister, 1972; Ribando et al., 1976). The high permeability in young oceanic crust 


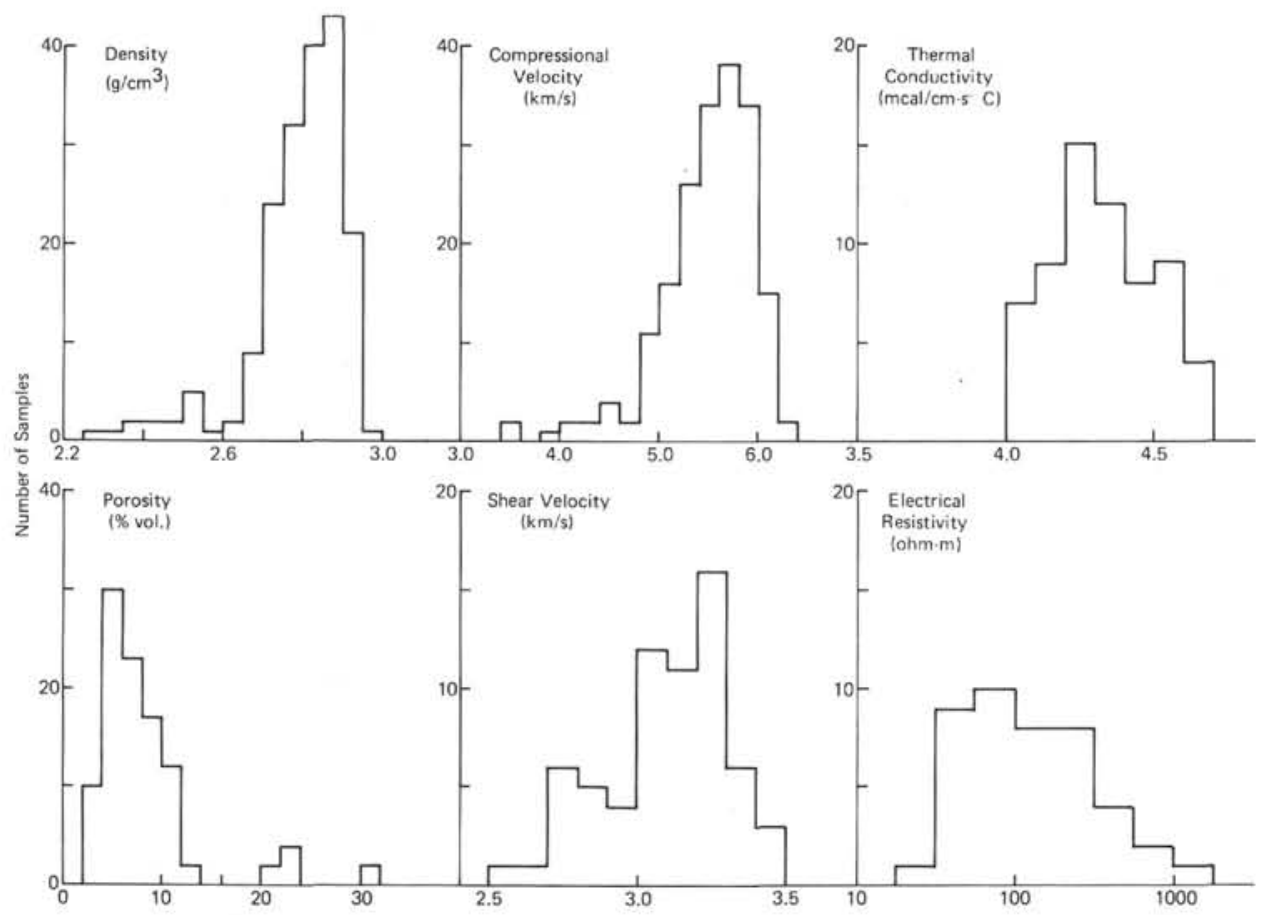

Figure 1. Physical property histograms for basalt samples from DSDP Holes $417 D$ and $418 A$.

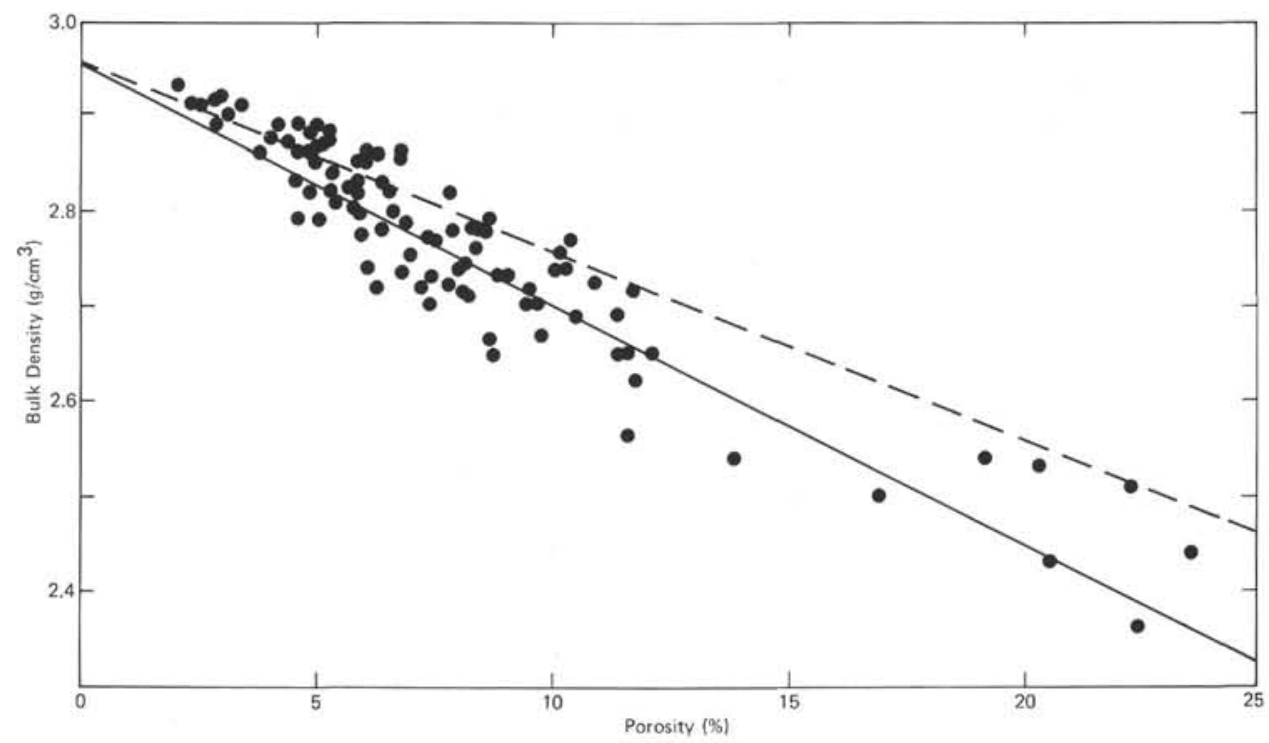

Figure 2. Bulk densities of samples from Holes 417D and 418A as a function of porosity. Solid line shows the least squares fit to the data. Dotted line shows theoretical variation of density with porosity (see text).

may be caused by large scale fractures or cracks as discussed previously. The in situ low velocity observed in Layer 2A (Hyndman, 1977) and the correlation between heat flow and the thickness of Layer 2A (Anderson et al., 1977) confirm this possibility. The present data, therefore, cannot be used directly to estimate the in situ permeability. It may have a direct bearing, however, on variations in low temperature alteration and cation deficiency in titanomagnetite in the rocks.

\section{COMPRESSIONAL WAVE VELOCITY UNDER PRESSURE}

The compressional wave velocity of some basalt samples was measured under hydrostatic confining pressures of 0 to $1 \mathrm{kbar}$. Although the samples were saturated with sea water, the pore pressure was kept close to atmospheric pressure during the experiments by surrounding the samples with a metal screen. Laboratory velocities under hydrostatic pres- 


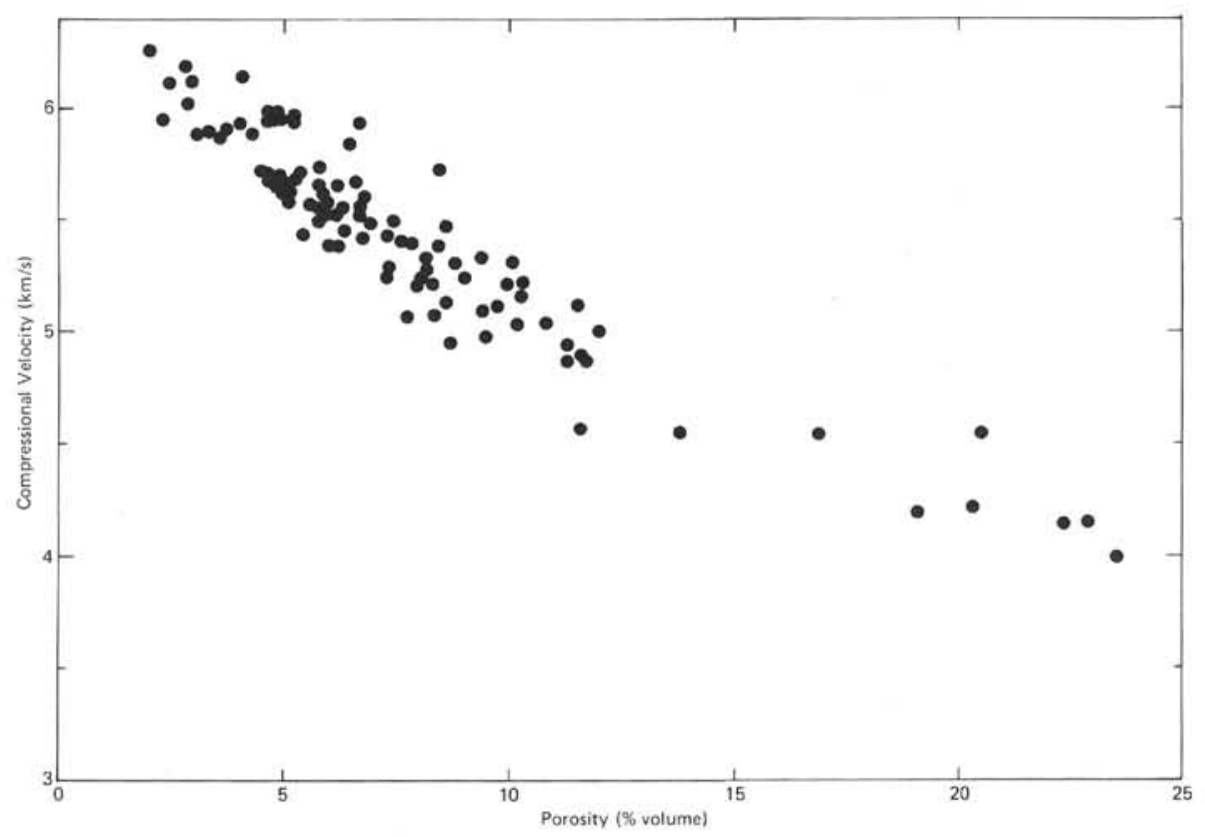

Figure 3. Compressional wave velocity versus porosity for Holes $417 \mathrm{D}$ and $418 \mathrm{~A}$.

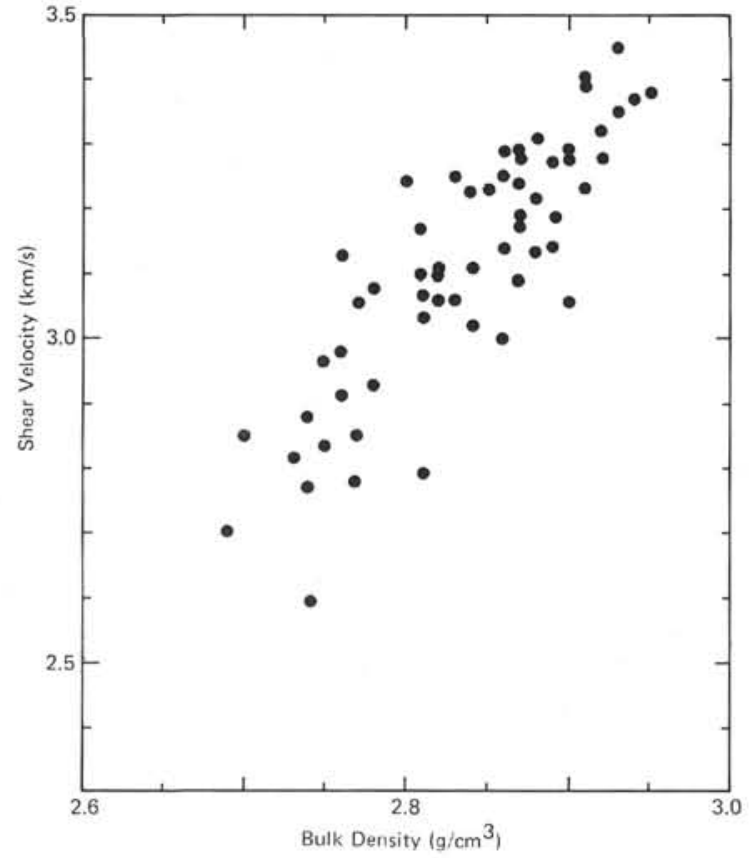

Figure 4a. Variation of shear wave velocity with density for basalt samples from Holes $417 D$ and $418 A$.

sure have been measured on a large number of oceanic basalt samples obtained by drilling or dredging (Christensen and Salisbury, 1975; Hyndman, 1977). In these experiments the pressure varied from 0 to $10 \mathrm{kbar}$. Under in situ conditions oceanic basement rocks are probably saturated with sea water at a pore pressure which varies between lithostatic and hydrostatic pressures (Brace, 1971). Thus, at the bottom of Layer 2, the pore pressure probably varies between 700 and 1000 bars and the effective pressure, i.e., the total pressure minus pore pressure, varies between 0 and 300 bars. In the present experiments, therefore, the velocity

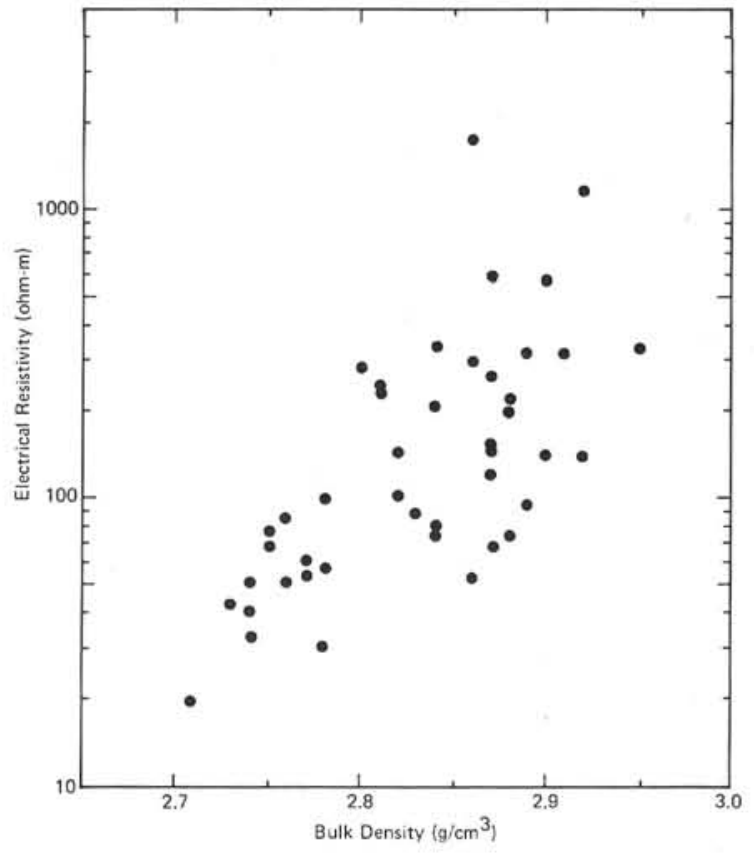

Figure 4b. Variation of electrical resistivity with density for samples from Holes $417 \mathrm{D}$ and $418 \mathrm{~A}$.

change in the low pressure range was carefully examined.

The results of these measurements are shown in Figure 7. The velocity increase is small and occurs largely between 0 and 300 bars. It is to be noted that the amount of the velocity increase is relatively constant and that the velocity of the low velocity samples remains low even at $1 \mathrm{kbar}$ pressure. This type of velocity variation has been observed previously for oceanic basalts (Salisbury and Christensen, 1976) and electrical resistivity data have been shown to display a similar pressure variation (Drury, 1976). This behavior is quite different from that of continental rocks, in which the 


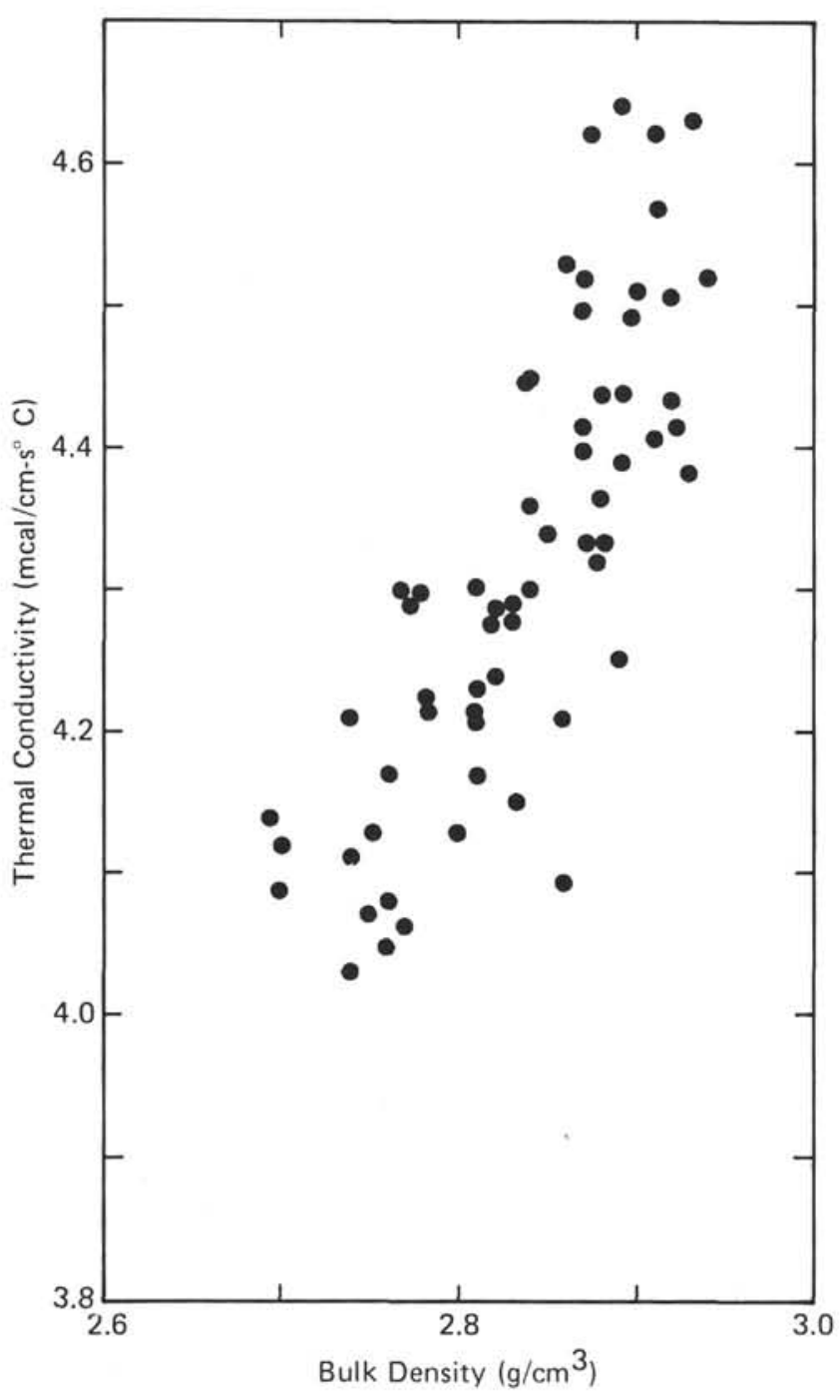

Figure 4c. Variation of thermal conductivity with density for samples from Holes 417D and 418A.

velocities commonly increase to pressures as high as $2 \mathrm{kbar}$ (Birch, 1960; Kanamori and Mizutani, 1965). Since the intrinsic velocities of the present samples appear to be rather similar, low velocity materials may be responsible for the low velocities observed in some samples under pressure. One possibility is that the low fluid permeability of the rocks prevents draining of the pore fluid during the duration of the experiment ( $\sim 2$ hours). If this is the case, the observed variation of velocity with pressure cannot be used to estimate the in situ velocity of these rocks. At least one line of evidence indicates, however, that this is not the case: in one run of the experiments, a confining pressure of $1 \mathrm{kbar}$ was maintained on a sample for about three days, but no appreciable change of velocity was observed. Following this experiment, the velocity was then measured as a function of pressure without the surrounding screen (i.e., the pore pressure was close to the external pressure). The variations in velocity with pressure for these two pore pressure conditions are compared in Figure 8. The small velocity increase in the latter case indicates that the flow of

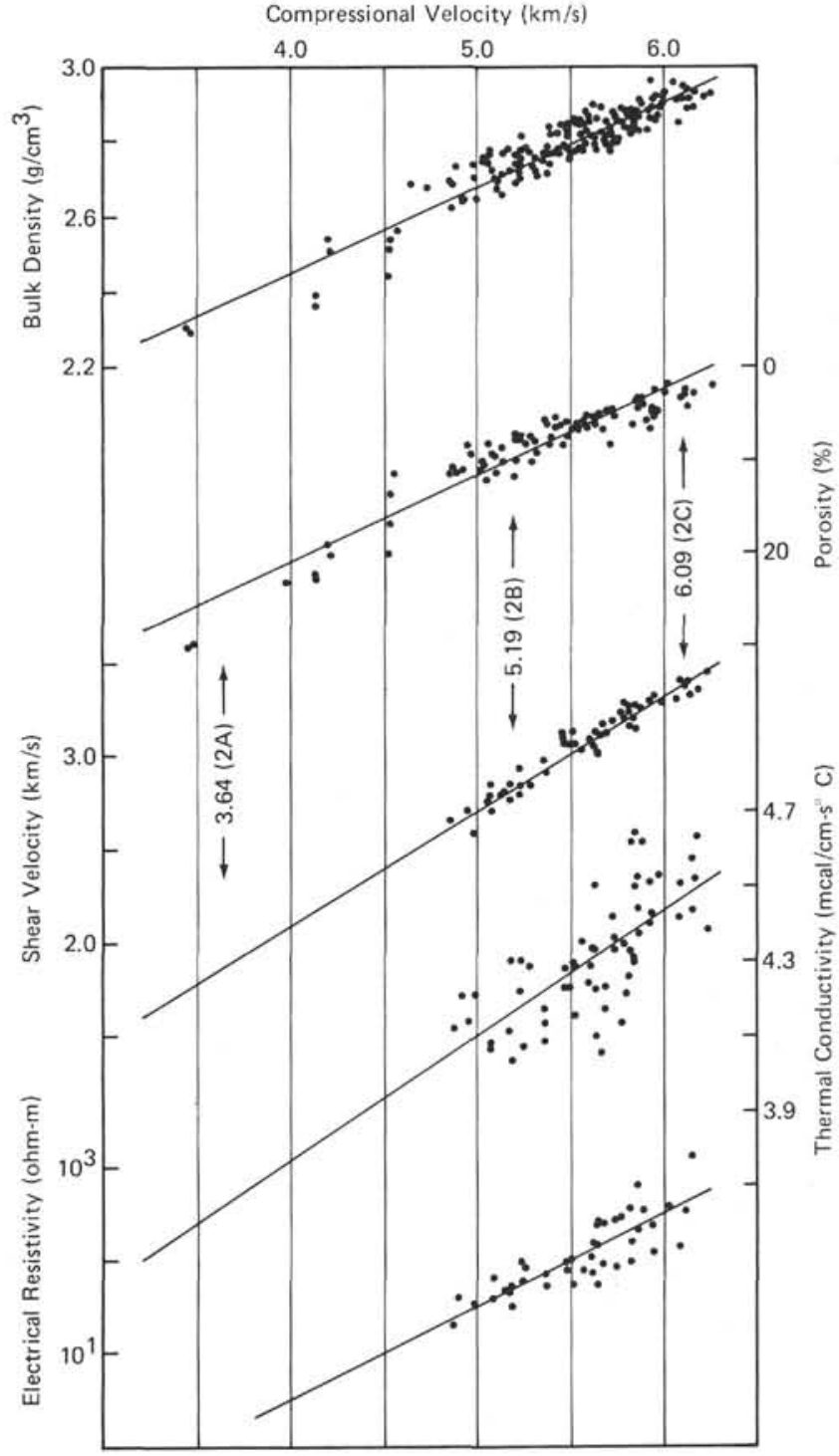

Figure 5. Variations of shear wave velocity, density, porosity, thermal conductivity, and electrical resistivity as a function of compressional wave velocity. Mean compressional wave velocities of Layers $2 A, 2 B$, and $2 C$ are indicated by arrows.

water in the samples really controls the observed velocity change.

From the above evidence it can be concluded that the permeability of the rocks is not small enough to prevent the flow of pore water within the sample. The observed permeabilities of some samples (Table 3 ) also support this conclusion. Thus, low velocity materials such as clay minerals may be responsible for the low velocities observed in some samples. The existence of clay minerals is also inferred from the density-porosity relation discussed above. If this is the controlling mechanism, the observed pressure variation can be applied to estimate the in situ velocity. From Figure 7, it is clear that the velocity increase at the bottom of layer 2 (i.e., the increase between 0 and 300 bars) 


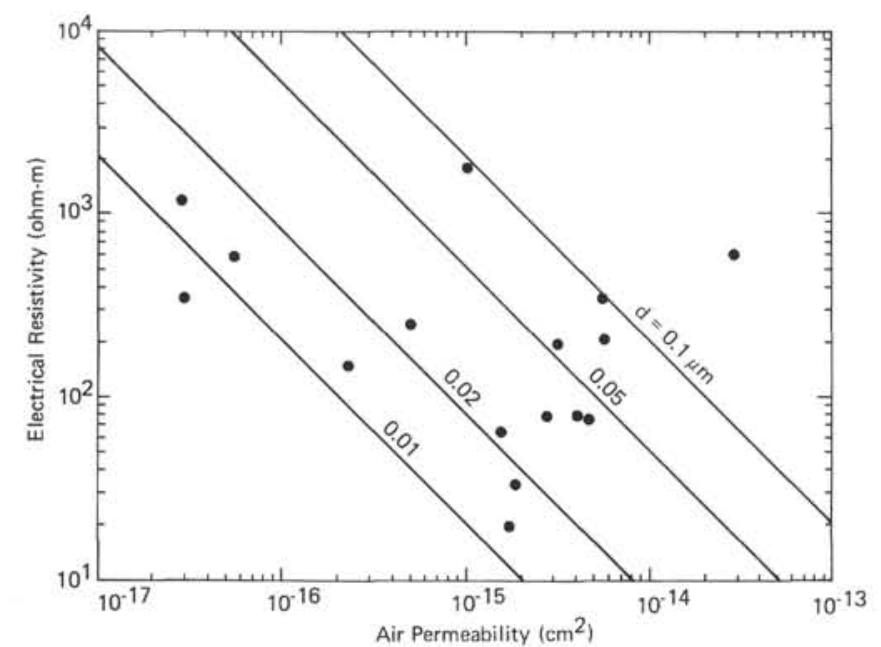

Figure 6. Relationship between air permeability and electrical resistivity in samples from Holes $417 \mathrm{D}$ and $418 \mathrm{~A}$. Solid lines show effective pore width calculated from Equation 3 in text.

is about 3.5 per cent, and is nearly independent of the initial velocity.

\section{ROCK COMPOSITIONS IN LAYER 2}

From seismic refraction experiments, Layer 2 has been subdivided into Layers 2A, 2B, and 2C (Houtz and Ewing, 1976). Although the division is not clear and the velocity range within each layer is broad and overlapping, the mean velocity increases with depth in Layer 2 and the top Layer, $2 \mathrm{~A}$, is characterized by low velocities (about $3.6 \mathrm{~km} / \mathrm{s}$ ). Layer $2 \mathrm{~A}$ does not always exist under the ocean floor. In the Atlantic Ocean, for example, the layer is not observed at Sites 417 and 418 and the recovered basement rocks are considered to be samples from Layer 2B. In contrast, the other deep basement penetration sites drilled to date in the Atlantic, such as Holes $332 \mathrm{~B}$ and $395 \mathrm{~A}$, were drilled into Layer $2 \mathrm{~A}$ in young crust. Thus, Holes 417D and 418A present the first opportunity to compare basement rocks from Layer $2 \mathrm{~B}$ with those from $2 \mathrm{~A}$. The data from Hole $332 \mathrm{~B}$ is best suited for such a comparison both because the hole is the deepest drilled in basement to date and because the data are presently available (Hyndman, 1977; Hyndman and Drury, 1977). The average physical properties of the Leg 37 basalt samples obtained by Hyndman and Drury (1976) are shown in Table 2. Some caution is necessary in comparing the two sets of data. The velocities in the Leg 37 basalt samples were obtained at a confining pressure of 0.5 kbar whereas the present measurements were made at one atmospheric pressure.

The observed ranges and the means of the bulk density, the porosity, and the electrical resistivity in both sets of measurements are similar and no systematic discrepancy is observed. After taking into consideration the mean velocity increase of about 4 per cent at $0.5 \mathrm{kbar}$ confining pressure (Figure 6), the observed velocities are also similar. The thermal conductivity data show some discrepancies, but the difference of the mean values is less than 10 per cent. The above comparison indicates that the physical properties of

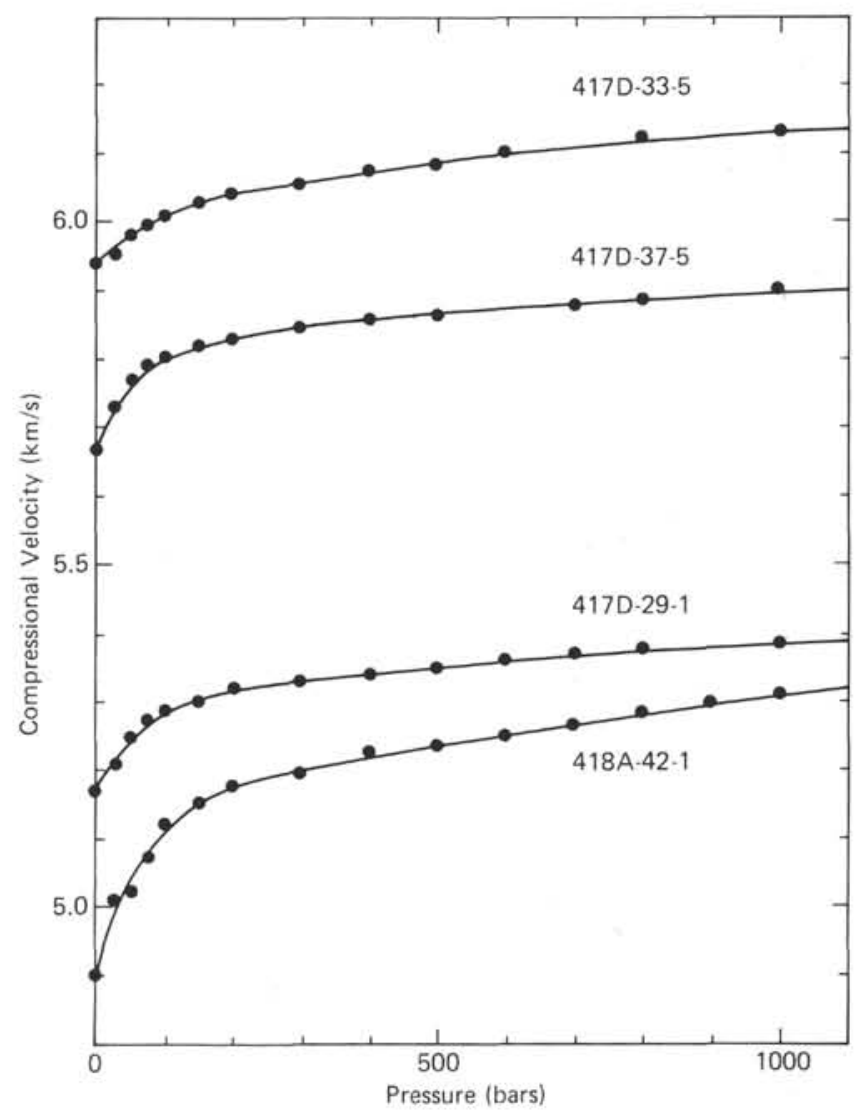

Figure 7. Measured compressional wave velocities for watersaturated samples from Holes $417 \mathrm{D}$ and $418 \mathrm{~A}$ as a function of confining pressure.

the basalt samples from Layers $2 \mathrm{~A}$ and $2 \mathrm{~B}$ are not significantly different from each other. The mineral or chemical compositions are also similar (Site Reports, this volume). The rock compositions of Layers $2 \mathrm{~A}$ and $2 \mathrm{~B}$ are therefore considered to be similar. Thus, as concluded by Hyndman (1977), the observed low velocity in Layer 2A is probably caused by the presence of large scale fractures or cracks.

Although Layer $2 \mathrm{C}$ has not been drilled, some inferences concerning its composition can be drawn from the present observations. The in situ velocity in Layer $2 \mathrm{C}$ ranges from about $6.0 \mathrm{~km} / \mathrm{s}$ to $6.5 \mathrm{~km} / \mathrm{s}$ (Houtz and Ewing, 1976). The highest laboratory velocity observed in low porosity basalts (less than $3 \%$ ) is within this range, which indicates that Layer 2C may be composed of relatively crack-free low porosity basalts.

From the foregoing discussion it is not unreasonable to assume that Layer 2 is mainly composed of extrusive pillow and massive basalt flows, as inferred from observations in ophiolite complexes (Christensen and Salisbury, 1975). The differences in mean velocity between Layers $2 \mathrm{~A}, 2 \mathrm{~B}$, and $2 \mathrm{C}$ are mainly caused by differences in porosity or the water content in the formation. The difference between Layers $2 \mathrm{~A}$ and $2 \mathrm{~B}$ is probably caused by large scale pores or fractures as discussed above. From a comparison of the present data with the results of logging (Salisbury et al., this volume) and the oblique seismic experiment (Stephen et al., this 


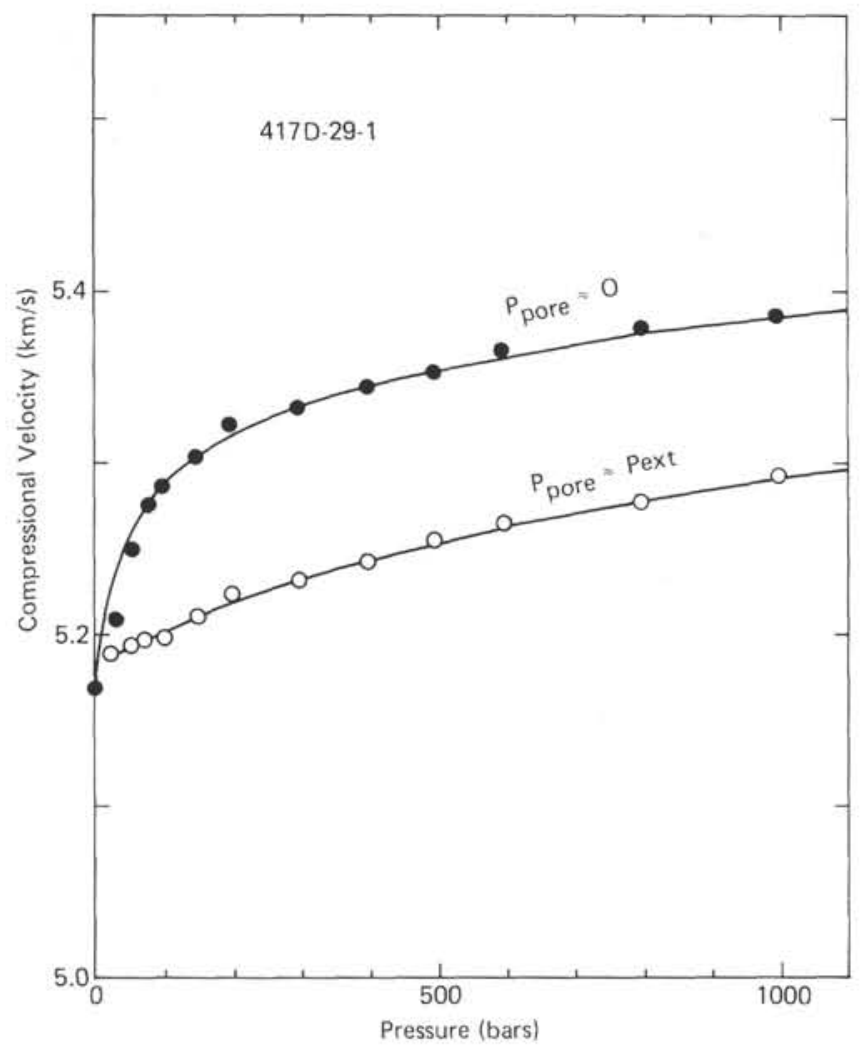

Figure 8. Measured compressional wave velocities for two pore pressure conditions $\left(P_{\text {pore }} \approx 0\right.$ and $\left.P_{\text {pore }} \approx P_{\text {ext }}\right)$ as a function of confining pressure.

volume) it is clear that the spacing of such fractures, even in Layer $2 \mathrm{~B}$, ranges from 0.1 to 100 meters. The large increase in velocity with pressure, for pressures less than 300 bars, and the relatively small variation of the velocity at higher pressures may be a cause of the Layer $2 \mathrm{~B}$ to Layer $2 \mathrm{C}$ transition.

It should be added here that in situ velocity of Layer 3 cannot be explained in terms of the extrusive basalts reported here.

\section{IN SITU PHYSICAL PROPERTIES IN LAYER 2}

It is clear from the preceding discussion that the physical properties of the basalts examined in this study correlate closely with each other. This can be easily explained if the variations in physical properties observed are mainly controlled by the porosity or water content of the samples. Since the structure of the oceanic crust has been mainly determined from seismic velocities obtained by refraction experiments, the other physical properties of the crust are only indirectly known. If the present basalt samples are representative of Layer 2, as concluded in the preceding section, the relations between the physical properties can be used to estimate the in situ physical properties from observed seismic velocities.

In Figure 5 the physical properties observed in the laboratory are plotted against compressional wave velocity and straight lines are fitted to the data by the method of least squares. The mean velocities of Layers $2 \mathrm{~A}, 2 \mathrm{~B}$, and $2 \mathrm{C}$ are also indicated in the figure. Although the results are pre- liminary because other controlling factors such as temperature are not included, the plots allow the physical properties in Layer 2 to be approximated. It is to be noted that the first order effects of the confining pressure are included in the relations shown since the variations of the physical properties with pressure are largely determined by change in porosity or water content at low pressures. To improve approximation further, the change of pore shape with pressure should be included.

\section{SUMMARY AND CONCLUSION}

The range and mean of the measured compressional and shear wave velocity, bulk density, porosity, electrical resistivity, thermal conductivity, and air permeability of basalts drilled from Layer 2B in Holes 417D and 418A are comparable with those of basalts drilled from Layer $2 \mathrm{~A}$ and the compressional wave velocity of low porosity samples is nearly equal to that of Layer $2 \mathrm{C}$. These observations suggest Layer 2 consists mainly of pillow and massive basalt flows, similar to those recovered at earlier DSDP sites.

The variations of the observed physical properties correlate closely with each other, reflecting the variations in the porosity or the water content of the samples. By using these correlations, it has been possible to estimate the in situ physical properties of Layers $2 \mathrm{~A}, 2 \mathrm{~B}$, and $2 \mathrm{C}$ from the observed seismic velocity in each Layer.

\section{ACKNOWLEDGMENTS}

I wish to express my appreciation for the opportunity to participate on Leg 52 of the Deep Sea Drilling Project. I am indebted to T. Watanabe for use of the QTM-1 thermal conductivity meter, and to M. Murakami and the Japan Petroleum Exploration Co. for the use of the permeability test apparatus. I wish to thank M. Kono for valuable discussions and for critical reading of the manuscript.

\section{REFERENCES}

Anderson, R.N., Langseth, M.G., and Sclater, J.G., 1977. The mechanisms of heat transfer through the floor of the Indian Ocean, J. Geophys. Res., v. 82, p. 3391-3409.

Birch, F., 1960. The velocity of compressional waves in rocks to $10 \mathrm{Kbar}, 1, J$. Geophys. Res., v. 65, p. 1083-1102. 1961. The velocity of compressional waves in rocks to $10 \mathrm{Kbar}, 2$, Kbar, 2, J. Geophys. Res., v. 66, p. 2199-2224. , 1966. Compressibility; elastic constants, In Clark, S.P., Jr. (Ed.), Handbook of Physical Constants, The Geological Society of America, Inc., p. 97-173.

Boyce, R.E., 1976. Definitions and laboratory techniques of compressional sound velocity parameters and wet-water content, wet-bulk density, and porosity parameters by gravimetric and gamma ray techniques. In Schlanger, S.O., Jackson, E.D., et al., Initial Reports of the Deep Sea Drilling Project, v. 33: Washington (U.S. Government Printing Office), p. 931-958.

Brace, W.F., 1971. Resistivity of saturated crustal rocks to $40 \mathrm{Km}$ based on laboratory studies. In Hancock, J.G. (Ed.), The Structure and Physical Properties of the Earth's Crust: Geophys. Monogr. Ser.: Washington (AGU), v. 14.

1977. Permeability from resistivity and pore shape, $J$. Geophys. Res., v. 82, p. 3343-3349.

Brace, W.F., Walsh, J.B., and Frangos, W.T., 1968. Permeability of granite under high pressure, J. Geophys. Res., v. 73, p. 2225-2236.

Christensen, N.I. and Salisbury, M.H., 1975. Structure and constitution of the lower oceanic crust, Rev. Geophys., v. 13, p. 57-86. 
Drury, M.J., 1976. Electrical resistivity of basalts, Leg 34. In Hart, S.R., Yeats, R.S., et al., Initial Reports of the Deep Sea Drilling Project, v. 34: Washington (U.S. Government Printing Office), p. 549-552.

Houtz, R. and Ewing, J., 1976. Upper crustal structure as a function of plate age, J. Geophys. Res., v. 81, p. 2490-2498.

Hyndman, R.D., 1977. Seismic velocity measurements of basement rocks from DSDP Leg 37. In Aumento, F., Melson, W.G., et al., Initial Reports of the Deep Sea Drilling Project, v. 37: Washington (U.S. Government Printing Office), p. 373-388.

Hyndman, R.D., and Drury, M.J., 1976. The physical properties of oceanic basement rocks from deep drilling on the MidAtlantic Ridge, J. Geophys Res., v. 81, p. 4042-4052.

, 1977. Physical properties of basalts, gabbros, and ultramafic rocks from DSDP Leg 37. In Aumento, F., Melson, W.G., et al., Initial Reports of the Deep Sea Drilling Project, v. 37: Washington (U.S. Government Printing Office), p. 395-402.

Kanamori, H. and Mizutani, H., 1965. Ultrasonic measurement of elastic constants of rocks under high pressures, Bull. Earthquake Res. Inst. Tokyo Univ., v. 43, p. 173-194.

Katsube, T.J., Frechette, J., and Collett, L.S., 1977. Preliminary electrical measurements of core samples, DSDP Leg 37 . In
Aumento, F., Melson, W.G., et al., Initial Reports of the Deep Sea Drilling Project, v. 37: Washington (U.S. Government Printing Office), p. 417-421.

Lister, C.R.B., 1972. On the thermal balance of a mid-ocean ridge, Geophys. J. Roy. Astron. Soc., v. 26, p. 515-535.

Nafe, J.E. and Drake, C.L., 1968. Physical properties of rocks of basaltic composition. In Hess, H. (Ed.), The Poldervaart Treatise on Rocks of Basaltic Composition: New York (Interscience), p. 483-502.

Parkhomenko, E.I., 1967. Electrical Properties of Rocks: New York (Plenum Press).

Ribando, R.J., Torrance, K.E., and Turcotte, D.L., 1976. Numerical models for hydrothermal circulation in the oceanic crust, $J$. Geophys. Res., v. 81 , p. $3007-3012$.

Robertson, E.C. and Peck, D.L., 1974. Thermal conductivity of vesicular basalt from Hawaii, J. Geophys. Res., v. 79, p. 4875-4888.

Salisbury, M.H. and Christensen, N.I., 1976. Sonic velocities and densities of basalts from the Nazca Plate, DSDP Leg 34. In Hart, S.R., Yeats, R.S., et al., Initial Reports of the Deep Sea Drilling Project, v. 34: Washington (U.S. Government Printing Office), p. 543-546.

Scheidegger, A.E., 1960. The Physics of Flow Through Porous Media: Toronto (University of Toronto Press). 